erosion of the status of the average psychiatric nurse. There was obviously much support for her views judged by the audience's enthusiastic response.

The meeting was wound up by $\mathrm{Dr}$ Garry Blessed and $\mathrm{Mr}$ John Knight from Newcastle, who described the work of the Community Nurses in their area. Community Nursing had made an enormous contribution to psychiatry, particularly in the care of the chronic psychotic and geriatric patient. He showed the advantages of keeping certain sick old people at home supported by community nurses.

All in all an enjoyable day, and the fact that most of us kept awake to the end was a tribute to the quality of the performances.

Angela Walsh

\title{
ANNUAL SUBSCRIPTIONS
}

During October each member of the College was asked to sign a mandate for payment of the annual subscription by direct debit. The reason for the change is to simplify administration in a way that is convenient to members and eliminates the minor problems and misunderstandings which the Bankers' Order system has sometimes occasioned.

\section{United Kingdom}

The response to the request for the change to direct debiting was so gratifying that when all replies are received it is expected that few members will have chosen to retain the rather outmoded Bankers' Order system.

\section{Overseas Members}

The response of those overseas members maintaining a current account at a bank within the United Kingdom has been as good, if not better than that from members resident within the United Kingdom.

However, overseas members who do not maintain a bank account within the United Kingdom cannot avail themselves of the direct debit facility, and they are reminded that their currency exchange authorities may require sight of the following extract from the subscription Bye Laws:-

'SECTION VIII-Fees and Subscriptions

2. Fellows, Members and Affiliates shall pay annually by way of subscription .... seventy pounds, forty five pounds and twenty five pounds respectively ... Subscriptions in respect of each calandar year shall become payable on the first of January each year...' and to have evidence of the individual's membership of the College before allowing transmission of the subscription. If any individual member has difficulty and writes for a formal 'requirement to pay document' from the College, one will be sent.

\section{AMENDMENT TO REGULATION 23(B) OF MEMBERSHIP EXAMINATION}

At their meeting on 13 October, 1980, the Court of Electors approved the following amendment to Regulation 24 paragraph (b) which refers to the necessary three years of approved training. This will now read:

23(b) Two years' approved psychiatric training at recognized hospitals, together with one year's post-registration experience in the UK or Eire in general prac- tice or in medicine or paediatrics provided this was gained in a post approved by an appropriate Royal College or Faculty for purposes of general professional training.

Thomas BeWLeY,

Dean 